\title{
NDE of Titanium Alloy MMC Rings for Gas Turbine Engines
}

George Y. Baaklini

Lewis Research Center

Cleveland, Ohio

Larry D. Percival

Pratt \& Whitney

West Palm Beach, Florida

Robert N. Yancey

Advanced Research and Applications Corporation

Dayton, Ohio

and

Harold E. Kautz

Lewis Research Center

Cleveland, Ohio

Prepared for the

Tenth Biennial Conference on Reliability Stress Analysis and Failure Prevention

sponsored by the American Society of Mechanical Engineers

Albuquerque, New Mexico, September 19-22, 1993 


\title{
NDE OF TITANIUM ALLOY MMC RINGS FOR GAS TURBINE ENGINES
}

\author{
George Y. Baaklini \\ National Aeronautics and Space Administration \\ Lewis Research Center \\ Cleveland, Ohio \\ Larry D. Percival \\ Pratt \& Whitney \\ West Palm Beach, Florida \\ Robert N. Yancey \\ Advanced Research and Applications Corporation \\ Dayton, Ohio
}

and

\author{
Harold E. Kautz \\ National Aeronautics and Space Administration \\ Lewis Research Center \\ Cleveland, Ohio 44135
}

\begin{abstract}
Progress in the processing and fabrication of metal matrix composites (MMC's) requires appropriate mechanical and nondestructive testing methods. These methods are needed to characterize properties, assess integrity, and predict the life of engine components such as compressor rotors, blades, and vanes. For this paper, we investigated the capabilities and limitations of several state-of-the-art nondestructive evaluation (NDE) technologies in characterizing titanium MMC rings for gas turbine engines. We examined the use of NDE technologies such as x-ray computed tomography, radiography, and ultrasonics in identifying fabrication-related problems that cause defects in components. Acousto-ultrasonics was explored to assess degradation of material mechanical properties by using stress wave factor and ultrasonic velocity measurements before and after the burst testing of the rings.

We concluded that radiography and pulse-echo ultrasonics are viable imaging techniques for fast and complementary evaluation of the rings. Furthermore, acousto-ultrasonics can be useful in a comparative analysis with a standard ring and for intermittent evaluation during the life of the rings. X-ray computed tomography can identify the manufacturing steps resulting in poor quality components, guide machining of components to final dimensions, and lead structural and design engineers to realistic component life-prediction models.
\end{abstract}

\section{INTRODUCTION}

MMC's consisting of a titanium alloy cladding and a ceramicfiber-reinforced titanium alloy matrix core are being developed mainly for aeronautic propulsion components and are candidate compressor and turbine disks materials (Stephens, 1990). MMC's offer good oxidation resistance, low density, and hightemperature strength, in addition to operating at significantly higher temperatures than monolithic metals and superalloys. The use of MMC's reduces engine cooling requirements, engine weight, and consequently, fuel consumption (Petrasek, 1988 and 1989). An increase in engine performance and a decrease in cost are expected. MMC's can be used over temperatures ranging from $800^{\circ} \mathrm{C}$ to above $1370^{\circ} \mathrm{C}\left(1475^{\circ} \mathrm{F}\right.$ to above $\left.2500^{\circ} \mathrm{F}\right)$. Problems associated with MMC's include fiber-matrix CTE (coefficients of thermal expansion) mismatch, analytical modeling difficulties in conjunction with composite development, and lack of ductility/toughness of the matrix (Stephens, 1990). In addition to developing high CTE fibers for MMC's, it is necessary to identify failure and damage mechanisms so that better modeling and life prediction can be done.

Manufacturing of high-temperature MMC engine components calls for development of new nondestructive evaluation (NDE) methods and for upgrading existing NDE techniques. Previous work (Baaklini, 1992; and Yancey and Baaklini, 1993) in x-ray computed tomography (XCT) demonstrated capabilities and limitations for characterizing MMC specimens and subscale engine components, established related calibration data, and corroborated findings with scanning acoustic microscopy, radiography, and metallography. Acousto-ultrasonics (AU), also, has been of increasing interest for NDE of high-temperature composite structures. Previous work in AU (Lott and Kunerth, 1990; Dos Reis, 1991; Kautz and Lerch, 1991; Kautz and Bhatt, 1991; Kautz, 1992; and Tewari and Henneke, 1992) showed that the AU signals recovered are sensitive to the strength, texture, and damage state in these materials. In addition, they found that when plate waves are excited, axial, shear, and flexure moduli can be determined. All of these AU studies were done with thin plates or tensile specimens.

The present work examines capabilities and problems encountered in extending the AU technique to thick cross-section hardware geometries and investigates the use and application of XCT, x-radiography, and immersion c-scan ultrasonics for identifying fabrication flaws and for assessing thermomechanical degradation. 


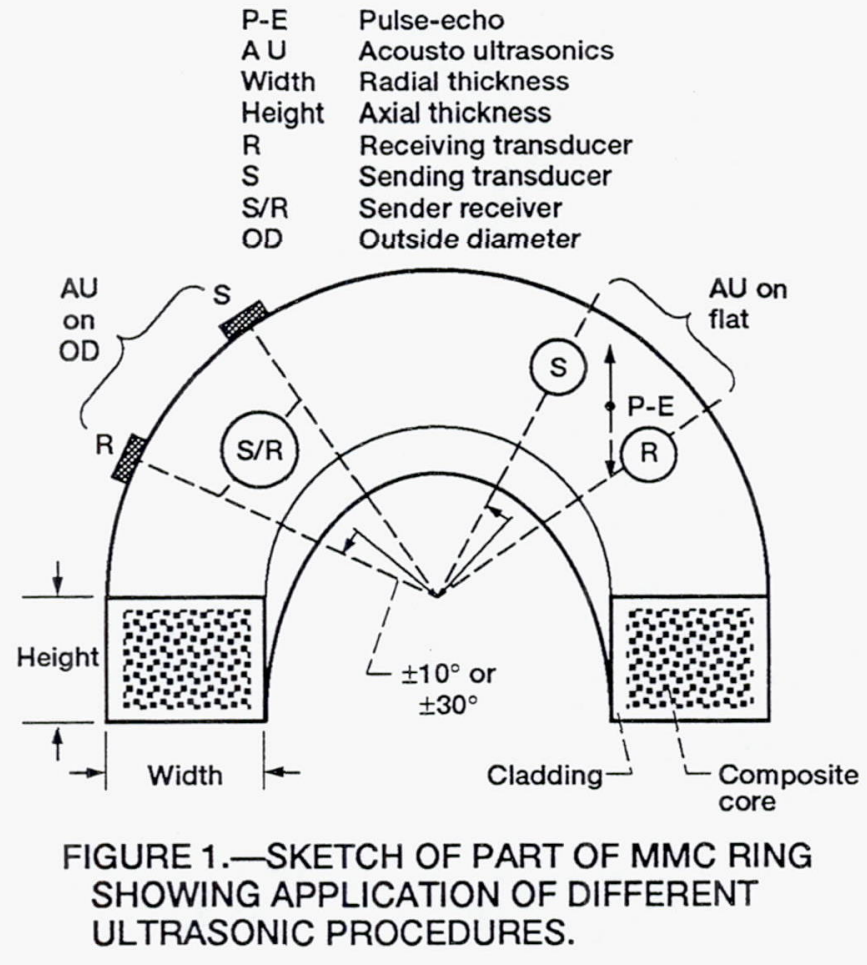

\section{EXPERIMENT}

Materials

Five Ti-clad, SCS-6 SiC-fiber-reinforced Ti alloy matrix core $\mathrm{MMC}$ rings were evaluated. Axial thicknesses ranged from 10 to $25 \mathrm{~mm}$ (0.4 to $1.0 \mathrm{in}$.) and radial thicknesses from 15 to $38 \mathrm{~mm}$ ( 0.6 to $1.5 \mathrm{in}$.). The outside diameter (OD) of these rings varied from 171 to $178 \mathrm{~mm}$ (6.75 to $7.0 \mathrm{in}$.). A part of an MMC ring is shown in Fig. 1.

Briefly, the manufacturing of these rings started with a bundle of SCS -6 filaments ( $142 \mu \mathrm{m}$ in diameter). The filaments were spirally wound with titanium ribbons (either Ti-15-3 for rings $\mathrm{R} 1, \mathrm{R} 2$, and R3, or Alloy C for rings R4 and R5) as they were inserted in a slotted titanium base disk to fabricate the ring. Titanium caps were welded to the top of the slotted disk for sealing. The sealed disks were consolidated by hot isostatic pressing. The consolidated composite disks were then machined into rings with 34 percent of fiber volume fraction. These compressor rings were designed for applications at $427^{\circ} \mathrm{C}\left(800^{\circ} \mathrm{F}\right)$.

Nondestructive evaluation was performed (1) before and after rings R1 to R4 were burst tested under an applied internal radial load (Gravett and Delaneuville, 1993) at room temperature or at $427^{\circ} \mathrm{C}\left(800^{\circ} \mathrm{F}\right)$ and $(2)$ only before metallographic sectioning of R5.

\section{Pulse-Echo Immersion Ultrasonics}

All ultrasonic inspections were conducted at $5 \mathrm{MHz}$ to achieve high signal-to-noise ratios and high resolution. All ultrasonic scans presented herein used a threshold setting amenable to resolving 0.8 -mm-equivalent diameter $(0.032$ in.) flat bottom holes (FBH's) with acceptable signal-to-noise ratio.

The pulse-echo (P-E) immersion ultrasonics were conducted with the transducers normalized and focused on the surface of the MMC ring. Either a KB6000 or a Sonic Mark VI was used as a pulser/receiver. Calibration was conducted by adjusting, with time-corrected gain, the amplitude responses from $1.2-\mathrm{mm}$ diameter $(0.48$ in.) FBH's ranging in depth from 19 to $38 \mathrm{~mm}$ ( 0.75 to 1.5 in.) in blocks of titanium alloy similar to the matrix material in the MMC rings (see Nondestructive Testing Methods Specifications). A compatibility check was conducted on each MMC ring to determine variability, relative to overall attenuation, between the MMC specimen and the monolithic calibration materials. This test involved monitoring the back surface response from both the MMC specimen and a calibration block of equivalent thickness. The instrument gain required to bring the back surface responses to 80 percent of screen height on the ultrasonic instrument was measured. Any difference in gain between the two materials was compensated for during the scan. Two scans at two sensitivity settings were then conducted. The first scan was set at the calibrated gain for a $1.2-\mathrm{mm}$ diameter ( 0.48 in.) FBH sensitivity. The second scan was conducted with an additional $7-\mathrm{dB}$ gain, an increase that provides for an equivalent 0.8 -mm-diameter $(0.032$ in.) $\mathrm{FBH}$ calibration. The following equation (Halmshaw, 1987) was used to make the 7-dB gain calculation:

$$
\Delta d B=20 \log \left(A_{1} / A_{2}\right)
$$

where $\mathrm{A}_{1}$ is the area of a $1.2-\mathrm{mm}$-diameter (0.048 in.) $\mathrm{FBH}$, and $\mathrm{A}_{2}$ is the area of an 0.8 -mm-diameter (0.032 in.) FBH.

Measurements were not taken at an equivalent $0.4-\mathrm{mm}$ diameter (0.016 in.) FBH because of signal-to-noise problems. A relatively good area on a MMC ring would show a signal response that was $24 \mathrm{~dB}$ or more below the calibration gain; it would appear as a light color (white) on the c-scan image. A c-scan is a plane view image displaying the variations in amplitude of the ultrasonic signal in ranges of gray as it maps an object while focusing at a specified depth. Each range in the $c$-scan image represents a change of $3 \mathrm{~dB}$ in response. P-E was applied to rings $R 1$ to $R 5$; however, only selected results will be discussed.

\section{Acousto-Ultrasonics}

Acousto-ultrasonics was done with two ultrasonic transducers on the same surface (Fig. 1). One transducer, the sender, introduced ultrasound and the other, the receiver, detected it after reverberating in the specimen. Broad-band immersion transducers with elastomer pads for coupling to the ring surface were deployed. Waveforms were digitized, stored, and processed as described by Kautz and Lerch (1991) and Kautz (1992). Data were collected with a combination $5.0 \mathrm{MHz}$ sender and $2.25 \mathrm{MHz}$ receiver and with a sender-receiver of 1.0 or $0.5 \mathrm{MHz}$.

For the stress-wave factor (SWF) and the pulse arrival measurements, data were collected, both before and after the mechanical test, with the transducer pairs coupled to the outer curved surface (OD) of the rings. In this configuration (Fig. 1) the transducer position and separation were referenced with respect to angular position from a fiduciary mark. Velocities in the fiber direction were measured only after the mechanical tests, by coupling the transducers to one of the flat faces of the rings (Fig. 1). In this case the position on the ring was still noted in terms of angle displacement, but transducer separation was measured in centimeters as a linear displacement across the face. Through-height (i.e., flat-to-flat) pulse-echo velocity 
measurements (normal to fibers) were also made. A $10.0-\mathrm{MHz}$ center frequency broad-band transducer was coupled to the ring with a gel. Although $A U$ was applied to rings R1, R2, and R3, only results from rings R1 and R3 will be discussed.

\section{X-Radiography and X-Ray Computed Tomography}

The XCT system is a laminography/dual energy (LAM/DE) computed tomography scanner. LAM/DE uses a translate-rotate scan geometry. Thus, the XCT scanning process consisted of translating the ring past the $\mathrm{x}$-ray beam, rotating it, and translating it past the $x$-ray beam again until the ring had been rotated $180^{\circ}$. LAM/DE includes a $420-\mathrm{kV}$ isovolt $\mathrm{x}$-ray source and a $\mathrm{CdWO}_{4}$ linear array detector with a $128-\mathrm{mm}$ field-of-view. The thickness of the XCT slice was $2 \mathrm{~mm}$, the image pixel size was $250 \mu \mathrm{m}$, the pixel integration time was $55 \mathrm{~ms}$, and the total scan time per slice was 20 to $30 \mathrm{~min}$. A conventional radiography system (400- $\mu \mathrm{m}$ focal spot size) with high energy capability up to $3.2 \mathrm{~kW}$ was also used.

\section{RESULTS \\ Pulse-Echo Ultrasonics}

Figure 2 shows the post test ultrasonic c-scan result of a portion of the SCS-6/Alloy-C ring R4 that was static-tested to failure at $427^{\circ} \mathrm{C}\left(800^{\circ} \mathrm{F}\right)$. This ring segment, which is located approximately $180^{\circ}$ from the burst location, contains internal damages due to the burst test. Metallography identified the "black" regions near the inner diameter of the ring in Fig. 2 as areas of damaged fibers. Figure 3 shows a metallographic cross section at a typical black region where a "notch" corresponding to ultrasonic findings guided metallographic sectioning. This cross section shows 18 damaged fibers, all located near the ID

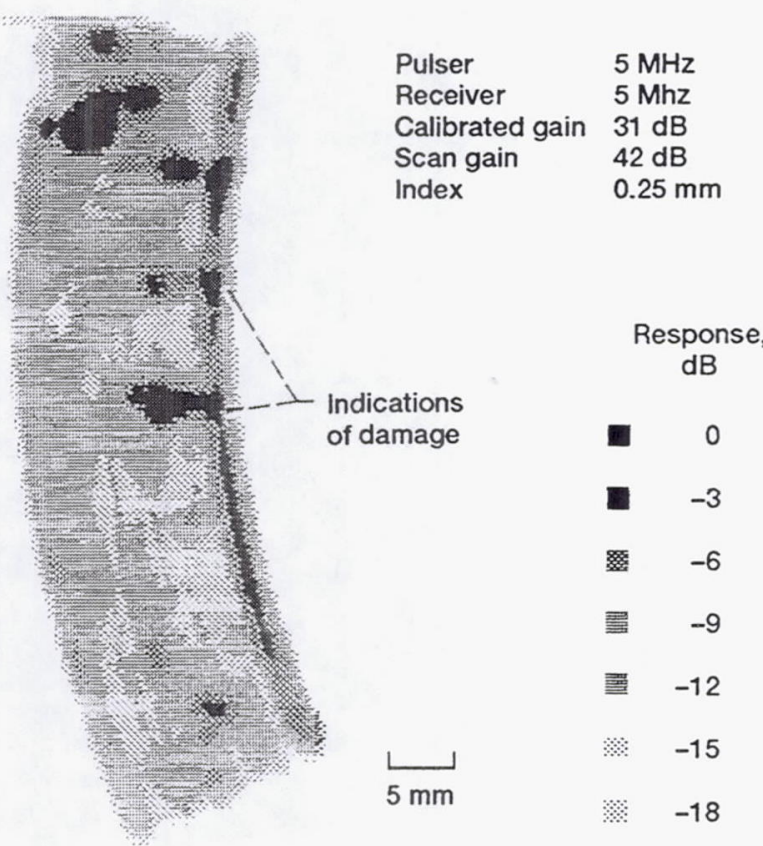

FIGURE 2.-SELECTED SECTION OF AN ULTRASONIC P-E SCAN OF SCS-6/ALLOY-C RING R4. BLACK REGIONS INDICATE MATERIAL DAMAGE. of the ring section. Higher magnifications of two of these fibers show varying degrees of damage (Fig. 4).

Figure 5 is an ultrasonic c-scan of a portion of ring R5. The matrix of this ring showed an increased ultrasonic response relative to other rings that were scanned at the same sensitivity before burst tests. This ring was not burst-tested. Ultrasonics, destructive testing, and metallographic sectioning revealed a great number of matrix pull-away conditions throughout the ring. Apparently, greater ultrasonic backscatter is produced by poor consolidation of the matrix material. Figure 6 is a micrograph of a polished typical area within the ring. Most of the fibers in Fig. 6 depict the matrix pull-away condition at the fiber matrix interface. Figure 7 shows higher magnification of this matrix pull-away condition. The cause of this condition has since been identified and successfully eliminated by a change in the consolidation sequence.

\section{Acousto-Ultrasonics}

Stress-Wave Factor. The acousto-ultrasonic SWF was calculated as the integral of the magnitude of the frequency spectrum. Although much ultrasonic or SWF energy passed from the $\mathrm{OD}$ to the ID of the rings and back, much was also trapped in the outer cladding. Since the energy passing into the composite core took longer to get to the receiver than that remaining in the outer cladding, the two paths could be separated by arrival time.

Parts (a) and (b) of Fig. 8 show the SWF's for a $5-\mathrm{MHz}$ sender and $2.25-\mathrm{MHz}$ receiver coupled to the outer surface of rings $R 1$ and $R 3$, respectively. The sender and receiver were $\pm 10^{\circ}$ apart with respect to a fiduciary mark. For both rings R1 and R3, the SWF was greater after the burst test. This is evidence that the burst test strained the cladding-composite interface and caused greater reflection of ultrasound back into the

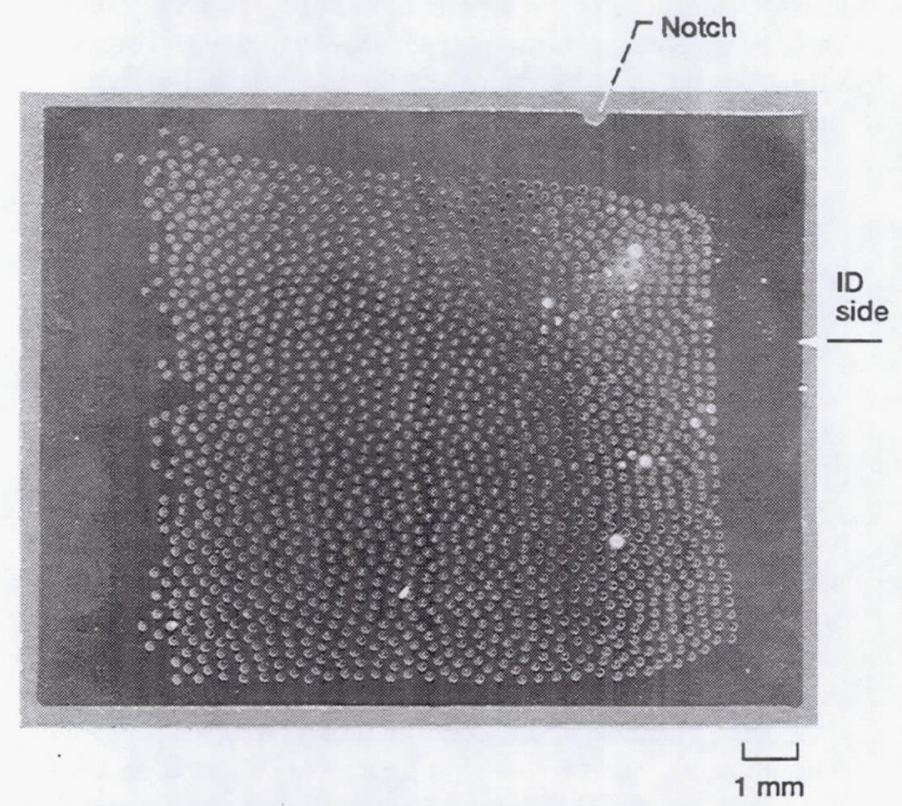

FIGURE 3.-TYPICAL METALLOGRAPHIC CROSS SECTION SHOWING FIBER DAMAGE WHERE ULTRASOUND EXHIBITED BLACK REGIONS IN RING R4. THE NOTCH WAS USED TO PINPOINT ULTRASOUNDINDICATED DAMAGE. BRIGHT WHITE FIBERS ARE THE DAMAGED FIBERS. 


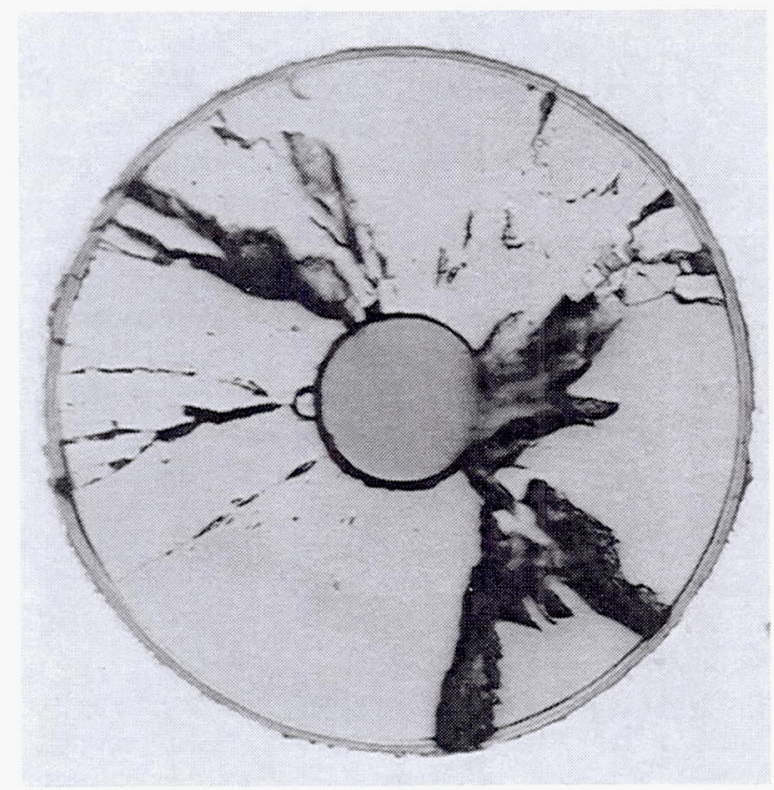

(a)

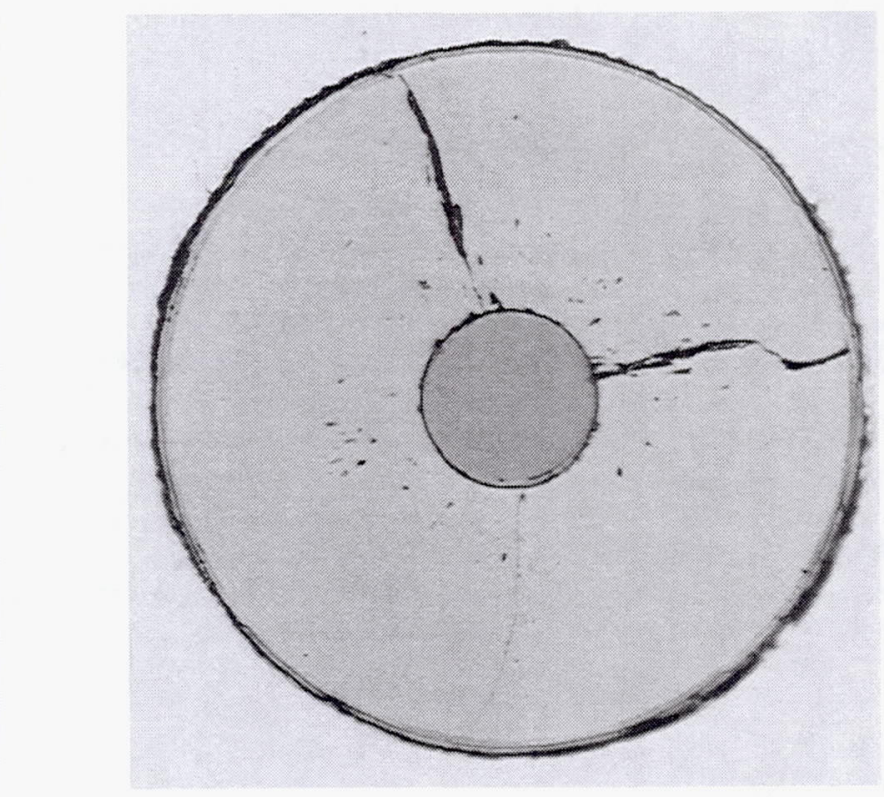

(b)

FIGURE 4.-PHOTOGRAPHS OF DAMAGED FIBERS FROM FIGURE 3 DEPICT (a) A CRUSHED FIBER AND (b) A CRACKED FIBER.

cladding. This reflected energy was less attenuated going from sender to receiver, thereby giving a greater SWF.

Similarly, Fig. 9 shows the SWF for only the initial portion (lower frequency) of the signals used in Fig. 8. This portion is strongly weighted by ultrasound that has passed in and out of the composite and thus does not show the increase in SWF after the burst test. Although there is more scatter in these data, Fig. 9(b) seems to indicate an actual decrease in SWF after the burst test.

Ultrasonic Velocity. In earlier work (Kautz and Lerch, 1991; and Kautz, 1992), 1-MHz transducers were found to excite the first symmetric Lamb mode in SiC/Ti-15-3 MMC's. The velocity of this mode is sensitive to the axial modulus in the propagation direction. When pairs of $1-\mathrm{MHz}$ transducers were coupled at $\pm 30^{\circ}$ from the fiduciary position on the outer face of the rings, the collected signals were dominated by discrete pulses. Figure 10 shows estimates of the reciprocals of arrival time as a function of position on rings R1 and R3 before and after the burst test. Figure 10(a) suggests a loss of modulus along the fiber direction near the crack in the failed ring R1. Figure 10 (b) demonstrates a general loss in the modulus along the fiber direction in ring $\mathrm{R} 3$ after the burst test.

Figure 11 shows results obtained with 1-MHz transducers, but only after the burst test. These data were collected on the flat face of the rings. For these, it was possible to calculate velocity. The magnitude of these velocities is in the range 0.6 to $0.8 \mathrm{~cm} / \mu \mathrm{s}$, as would be expected for the first symmetric Lamb mode mentioned previously. Figure 11 also includes the $10-\mathrm{MHz}$ pulse-echo results. All the velocities in Fig. 11(a) exhibit degradation in the vicinity of the crack in ring $\mathrm{R} 1$ as noted also with Fig. 10.

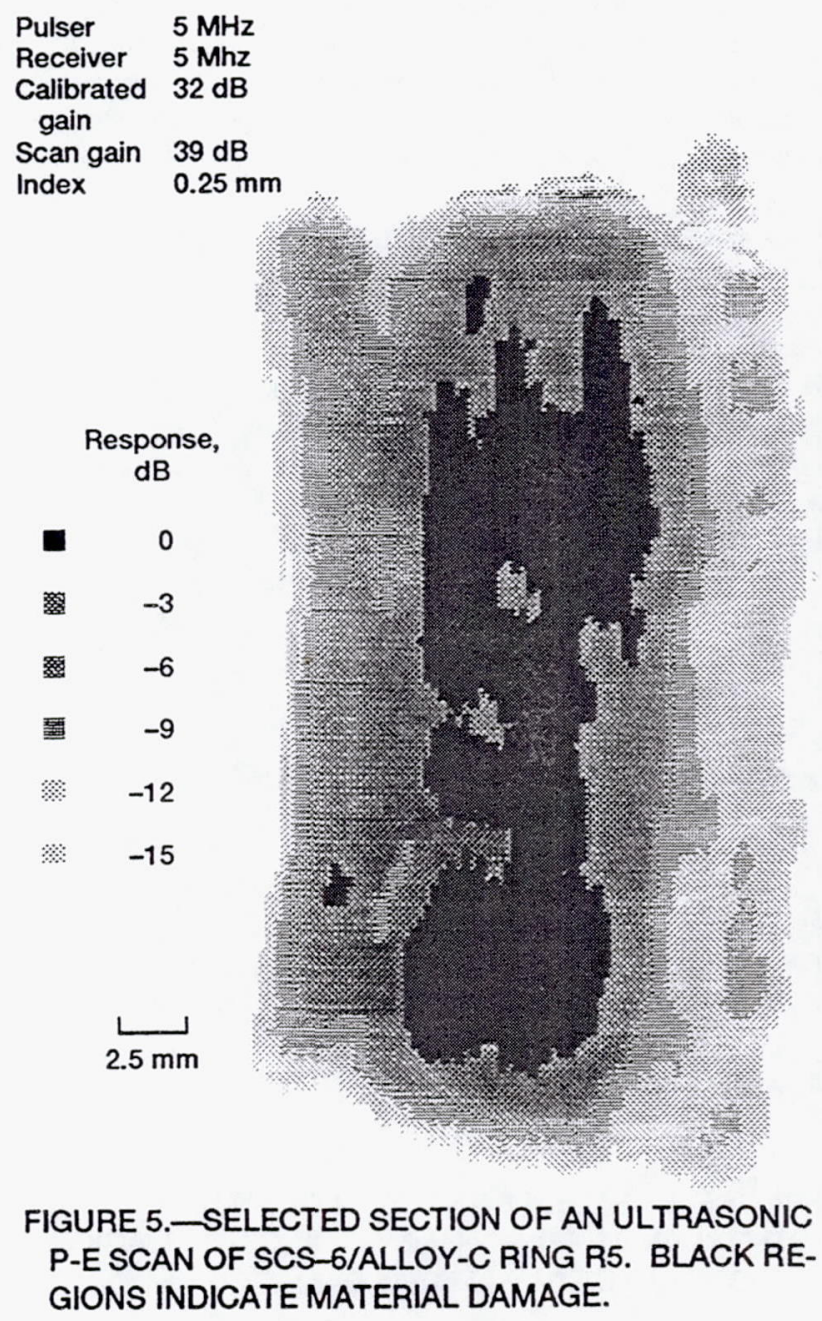




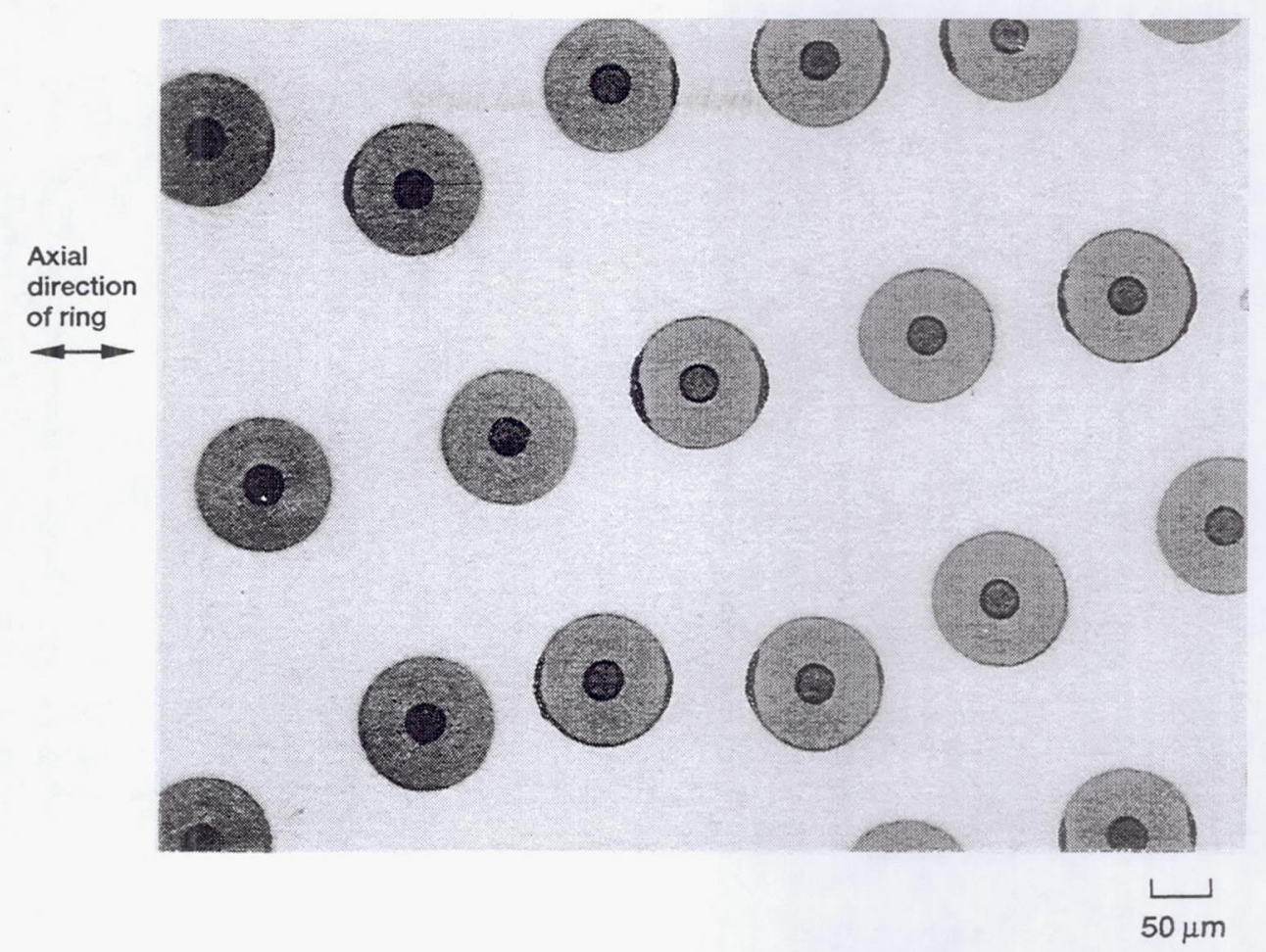

\section{FIGURE 6. -SELECTED MICROGRAPH SHOWING MATRIX PULL-AWAY CONDITION OF MATERIAL DAMAGE CHARACTERIZED BY ULTRASOUND IN FIGURE 5.}

Velocities in ring R3 (Figs. 10(b) and 11(b)) do not show sensitivity to anomalies $\mathrm{A}, \mathrm{B}$, or $\mathrm{C}$ that were found with radiography to be low density regions.

In earlier work, Kautz and Bhatt (1991) and Kautz (1992) used $0.5-\mathrm{MHz}$ transducers to excite the first antisymmetric Lamb mode in SiC/Ti-15-3 MMC's. The velocity of this mode is sensi-

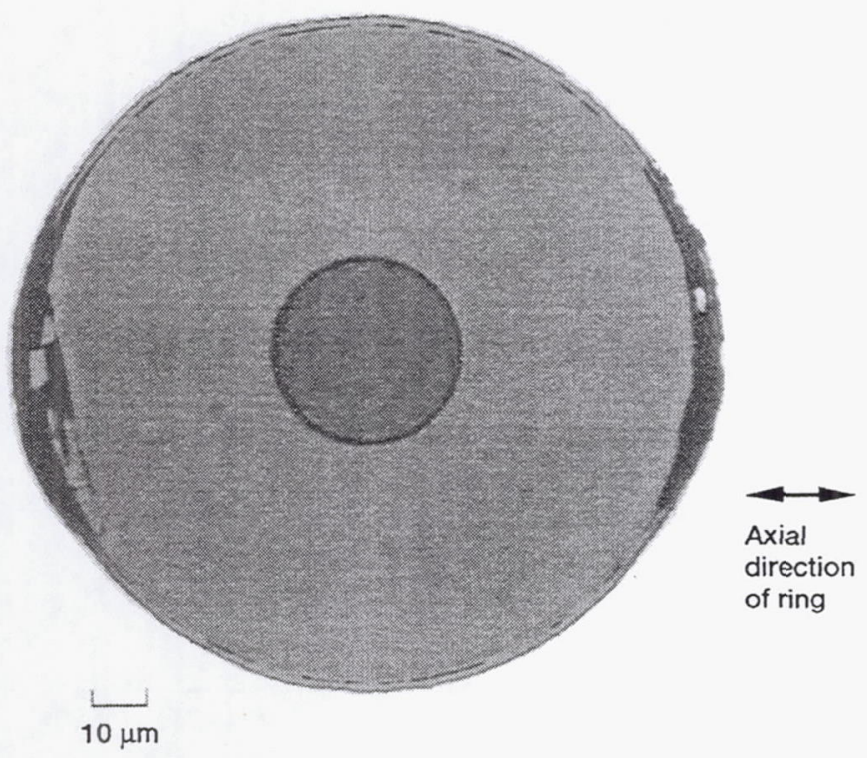

\footnotetext{
FIGURE 7.-HIGH MAGNIFICATION MICROGRAPH OF TYPICAL MATRIX PULL-AWAY CONDITION IN RING R5.
}

tive to shear and flexure stiffness in the propagation direction. Figure 12 shows velocities from pairs of $0.5-\mathrm{MHz}$ transducers coupled to the flat sides of the rings. These velocities ranged from 0.3 to $0.4 \mathrm{~cm} / \mu \mathrm{s}$. This supports the assumption that these are shear wave velocities. Figure 12(a) indicates degradation of the shear velocity in the vicinity of the crack in ring $\mathrm{R} 1$. Unlike the axial cases, Fig. 12(b) suggests some degradation in the shear velocity in the vicinity of anomalies $\mathrm{A}, \mathrm{B}$, and $\mathrm{C}$ that were identified by radiography.

Comparison of SWF to Velocity Results. AU waveforms showed that the ultrasound was trapped in the cladding layer. It is likely that the pulses used for the velocity calculations also remained in this layer. It is not surprising that plate waves were detected, because the cladding approximates a plate. Apparently some ultrasonic energy did pass to the core fibers. This is evidenced in Fig. 11 by the fact that velocities along the fiber direction are greater than velocities normal to the fiber direction.

\section{X-Radiography and X-Ray Computed Tomography}

Figures 13 and 14 show through-the-thickness conventional radiographs of rings $\mathrm{R} 2$ and $\mathrm{R} 3$ along with selected XCT slices. Conventional radiography showed a thinner cladding toward the ID of ring R2 than toward the OD. Similarly, the four XCT slices not only show a smaller cladding on the ID side than on the OD side, but also detail the density variations within each slice. Conventional radiography also shows the density variations within the composite core and features the presence of sizeable low density anomalies such as the one highlighted in Fig. 13 before the $120^{\circ}$ marker. 


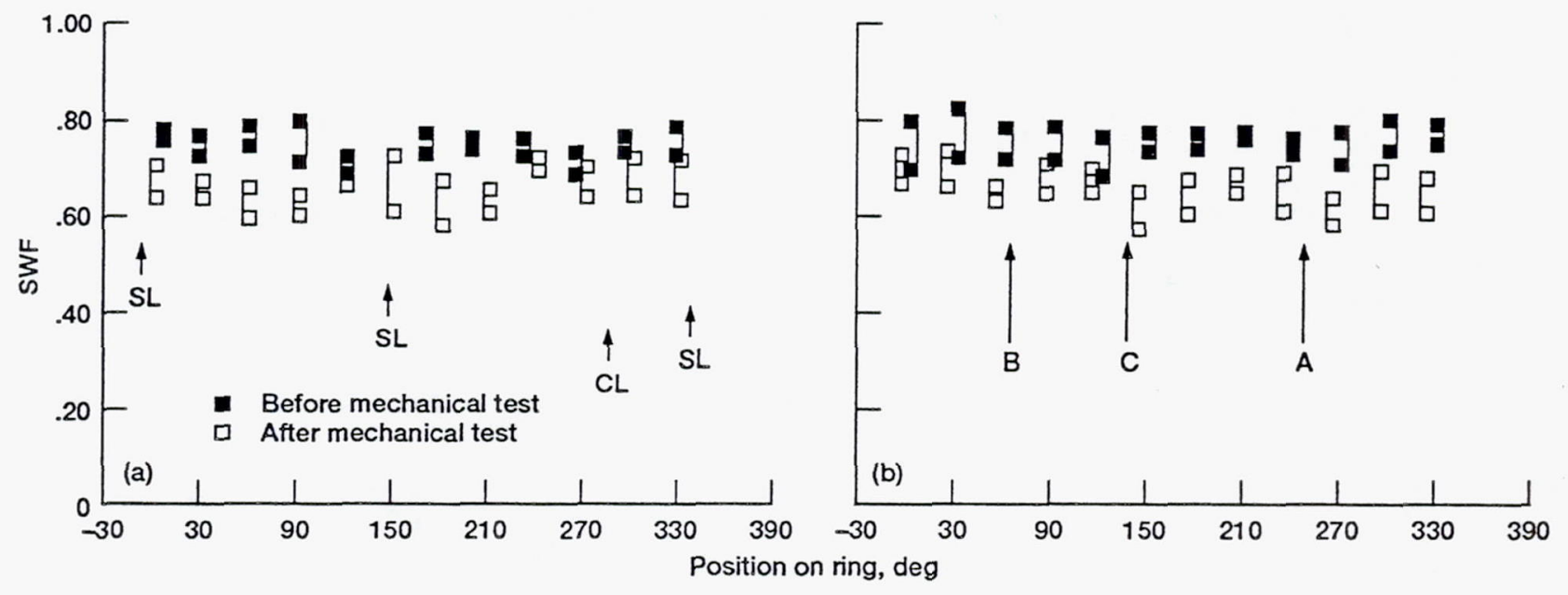

FIGURE 8.-SWF OF THE HIGHER FREQUENCY COMPONENT OF SIGNAL IN (a) RING R1 AND (b) RING R3. (SWF = RATIO OF INTEGRATED AREA OF MAGNITUDE SPECTRUM OF [0.8 TO $3 \mathrm{MHz}$ ] TO THAT OF [O TO $5 \mathrm{MHz}$ ]; SL = SEPARATION LOCATION; CL = CRACK LOCATION; A, B, C = ANOMALY LOCATIONS IN RADIOGRAPHS.)
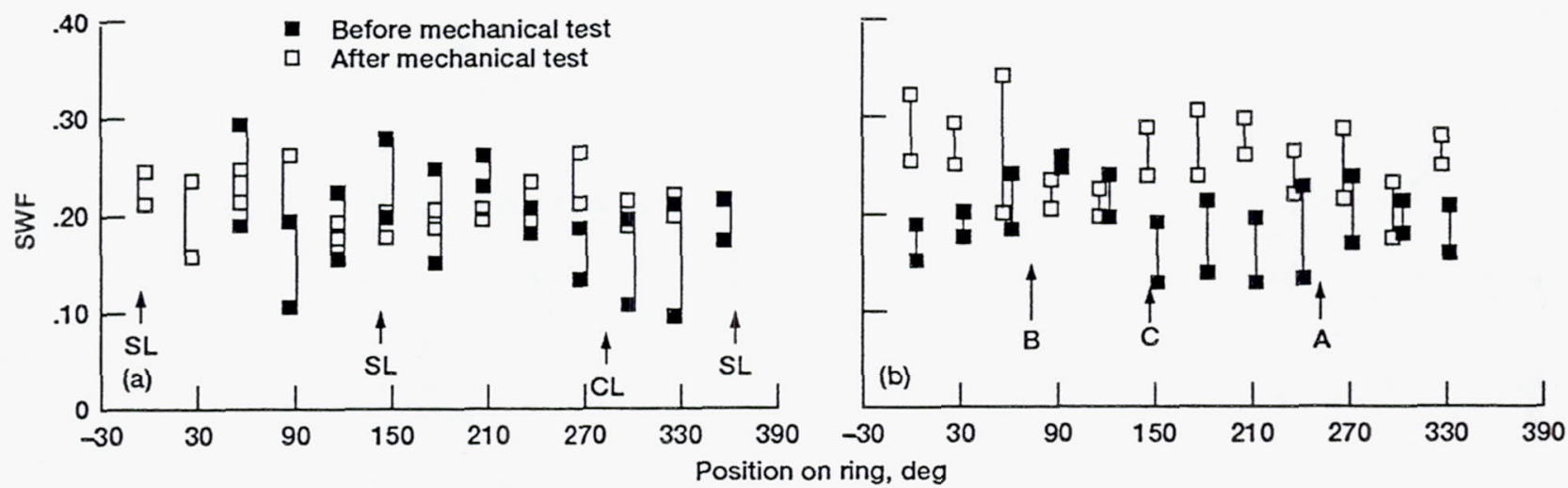

FIGURE 9. - SWF OF THE LOWER FREQUENCY COMPONENT OF SIGNAL IN (a) RING R1 AND

(b) RING R3. (SWF = RATIO OF INTEGRATED AREA OF MAGNITUDE SPECTRUM OF [0.2 TO $0.8 \mathrm{MHz}$ ] TO THAT OF [O TO $5 \mathrm{MHz}$; $\mathrm{SL}=$ SEPARATION LOCATION; CL = CRACK LOCATION; A, B, C = ANOMALY LOCATIONS IN RADIOGRAPHS.)

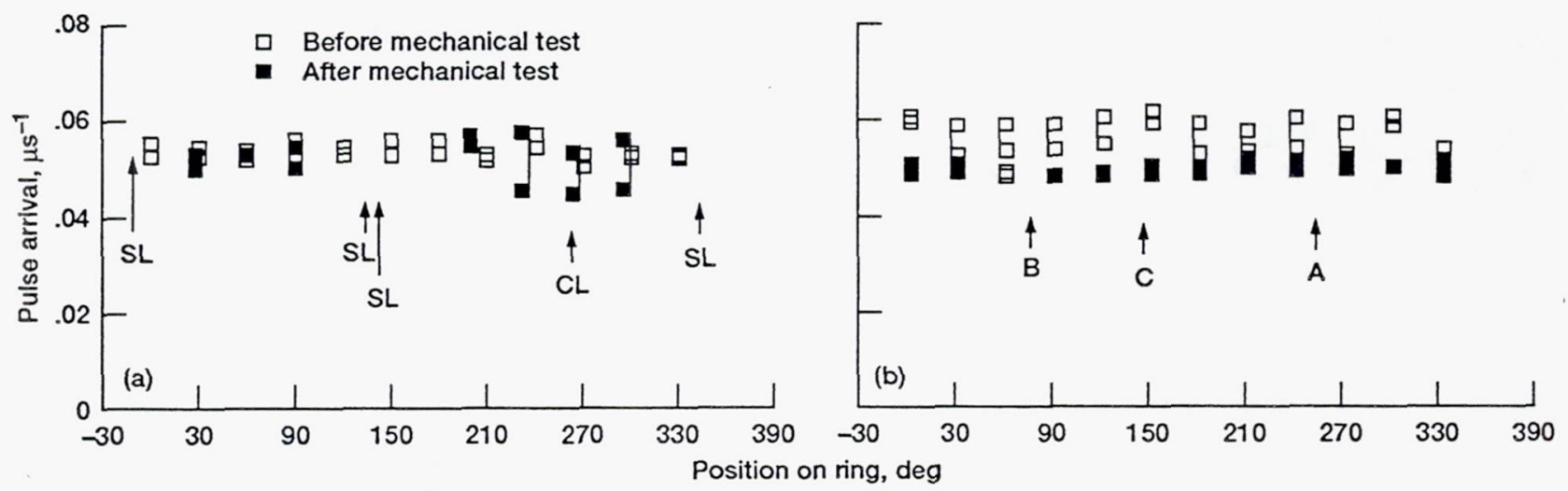

FIGURE 10.-PULSE ARRIVAL VERSUS POSITION ALONG THE OD OF (a) RING R1 AND

(b) RING R3. (SL = SEPARATION LOCATION; CL = CRACK LOCATION; A, B, C = ANOMALY LOCATIONS IN RADIOGRAPHS.) 

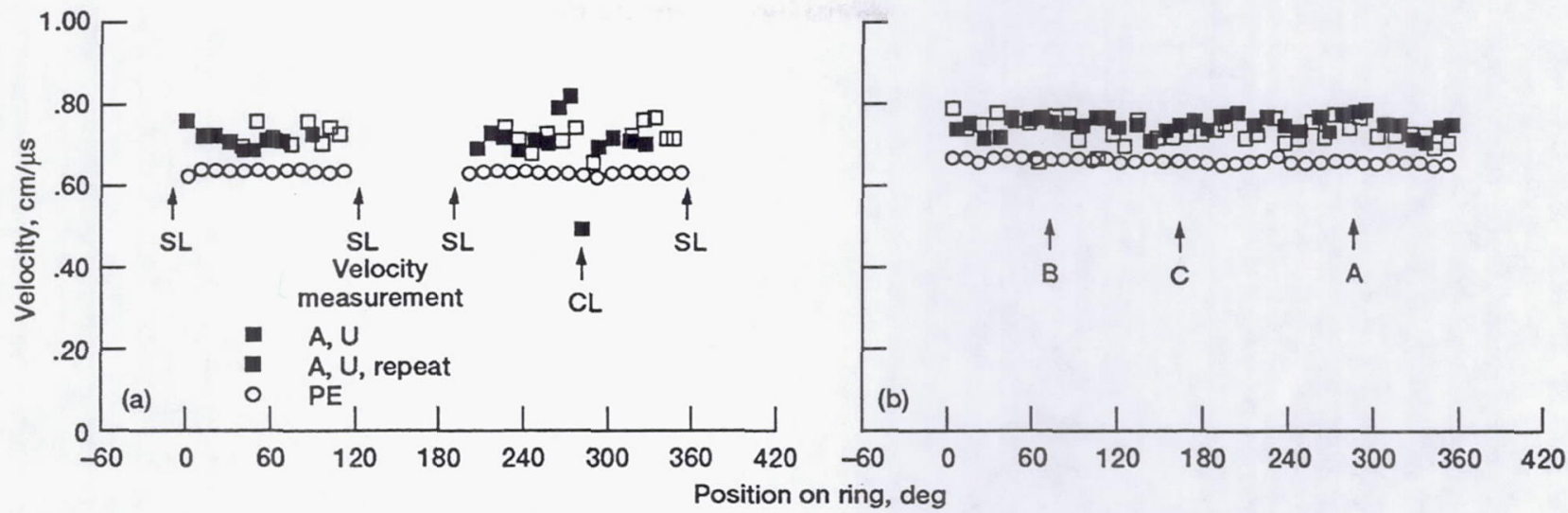

FIGURE 11.-VELOCITIES IN (a) RING R1 AND (b) RING R3. (SL = SEPARATION LOCATION; $\mathrm{CL}=$ CRACK LOCATION; A, B, C = ANOMALY LOCATIONS IN RADIOGRAPHS.)

The XCT slices in Figs. 13 and 14 depict the presence of a protruding cusp in the core, located near the top side and toward the ID of the ring. XCT slices further demonstrated a lower fiber volume fraction and/or poorer consolidation in the core area toward the OD side than is seen toward the ID side. The core of the composite was supposed to be rectangular, uniform, and surrounded by uniform cladding.

A magnified XCT image in Fig. 15 shows density variations in a slice of ring $\mathrm{R} 1$ before testing. The density variations along line AA show a 10-percent change between the case and the core of the ring and a 3-percent change within the composite core. Figure 15 reveals the processing/consolidation problems that resulted in the protruding cusp seen previously in rings R2 and R3. The horizontal white band in the core section indicates a manufacturing flaw (i.e., an extra foil layer).

Figure 16 presents radiographs with different magnifications of R2 before and after the burst test in order to compare results on the same figure. XCT slices taken before (A and D) and after (B and C) the burst test at approximately the same locations are also shown in Fig. 16. One location was near the burst area (i.e., the primary fracture (PF) area), and the other was near the secondary fracture (SF) area that is diametrically opposite the PF. Radiography of ring R2 before testing detected a defect condition that may have lead to the primary failure, because the location of that defect coincides with the location of the primary fracture designated LPF in Fig. 16. The defect has a low radiographic density that may indicate poor consolidation in the composite core and poor cladding-composite interface bonding. Radiography also showed poor consolidation and/or higher fiber volume fraction in the $\mathrm{OD}$ side of the core before and after testing. A defect appears in the radiograph taken after testing. This type of defect was also found with ultrasonics. Characterizing the defects, the difference in the degree of damage that is seen between XCT slices B and C, and the damage evolution that is seen between slices $A$ and $B$ and between $C$ and D requires further work. Future work will correlate NDE findings and detailed metallographic characterization.

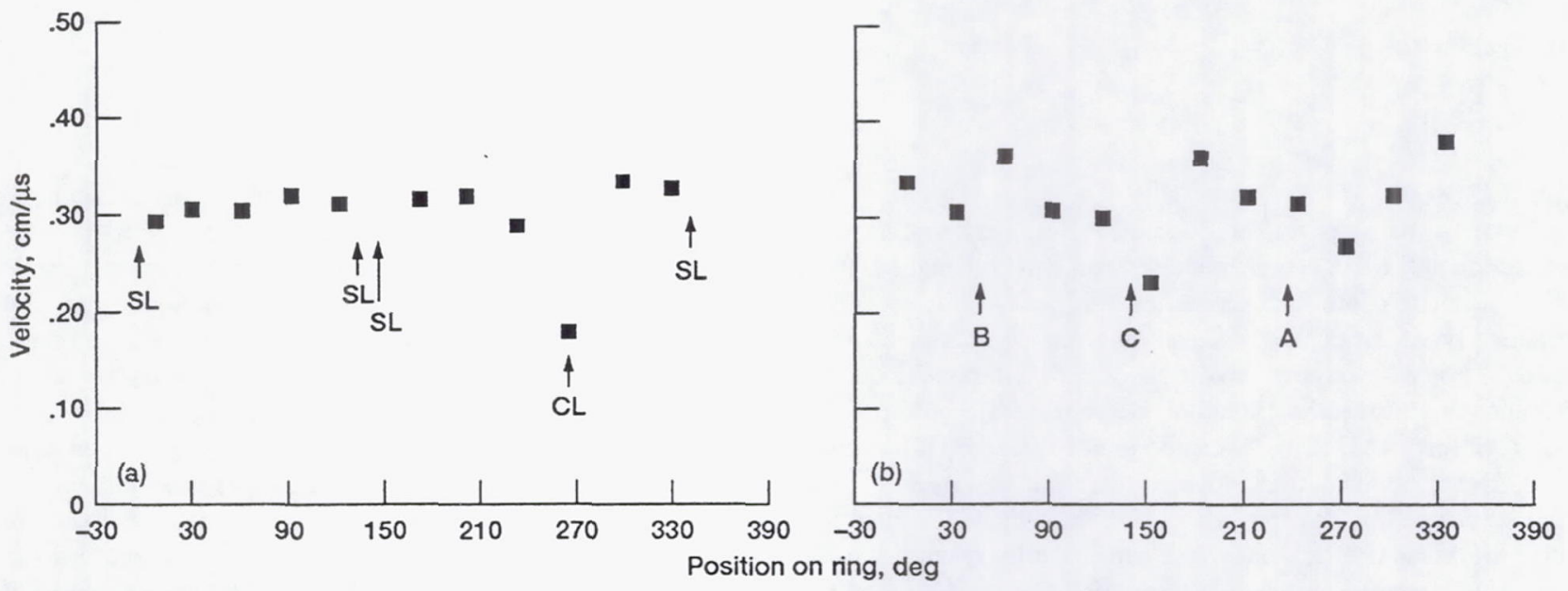

FIGURE 12.-SHEAR VELOCITIES FOR (a) RING R1 AND (b) RING R3. (SL = SEPARATION LOCATION; CL = CRACK LOCATION; A, B, C = ANOMALY LOCATIONS IN RADIOGRAPHS.) 


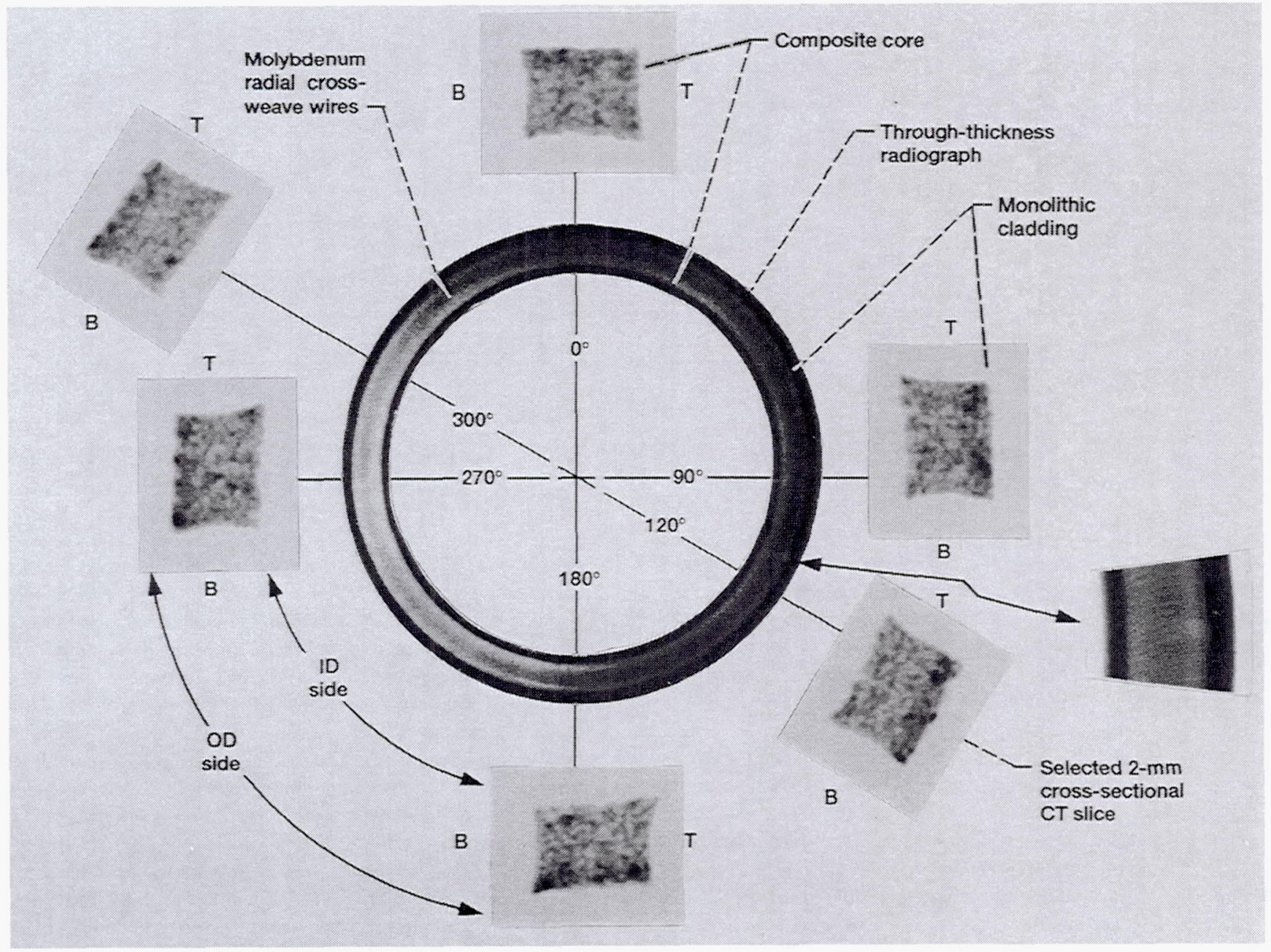

FIGURE 13.-RADIOGRAPHY AND X-RAY COMPUTED TOMOGRAPHY OF RING R2. (ANNULUS DIMENSIONS: OD, 171 MM; ID, 133 MM; THICKNESS, 24 MM; ANNULUS MATERIALS, SCS-6/TI-15V-3CR-3AL-3SN. T IS TOP SIDE; B IS BOTTOM SIDE.) LIGHTER REGIONS INDICATE HIGHER DENSITY IN TOMOGRAPHY (DARKER IN RADIOGRAPHY).

\section{DISCUSSION}

In the MMC rings studied, focused P-E immersion ultrasonic inspection at 5-MHz center frequency can detect damaged fibers and fiber-matrix interface anomalies. Further work is needed to evaluate types, sizes, and numbers of combined damage conditions. This will require investigation of different frequency domains and ultrasonic methodologies before life prediction of hoop reinforced MMC rings can be greatly aided by ultrasonics.

AU data showed that much of the ultrasonic energy was trapped inside the cladding. However, since the SWF increased after the burst test, it seems that some energy leaked into the core MMC material in the AU tests prior to burst testing. After failure, the cladding acted as a "wave guide" from sender to receiver.
$\mathrm{AU}$ velocity measurements along or perpendicular to the fiber direction, and P-E velocity measurements across the fiber direction showed a degradation at the crack location in ring R1. Velocity measurements before burst testing showed, at best, a discontinuity across the crack region. However, this does not unambiguously predict where the ring will crack since no such discontinuity is observed at the ring separations. Neverthless, AU velocity measurements are beneficial for degradation assessment during the life of the ring. Shear-like velocity measured on ring R3 seems to show some degradation at the three locations A, B, and $\mathrm{C}$ where radiography showed the presence of anomalies.

$\mathrm{XCT}$ density information is recognized as a means of guiding structural analysis. Distortions in composite constituents, which may cause nonuniform material responses at high temperatures 


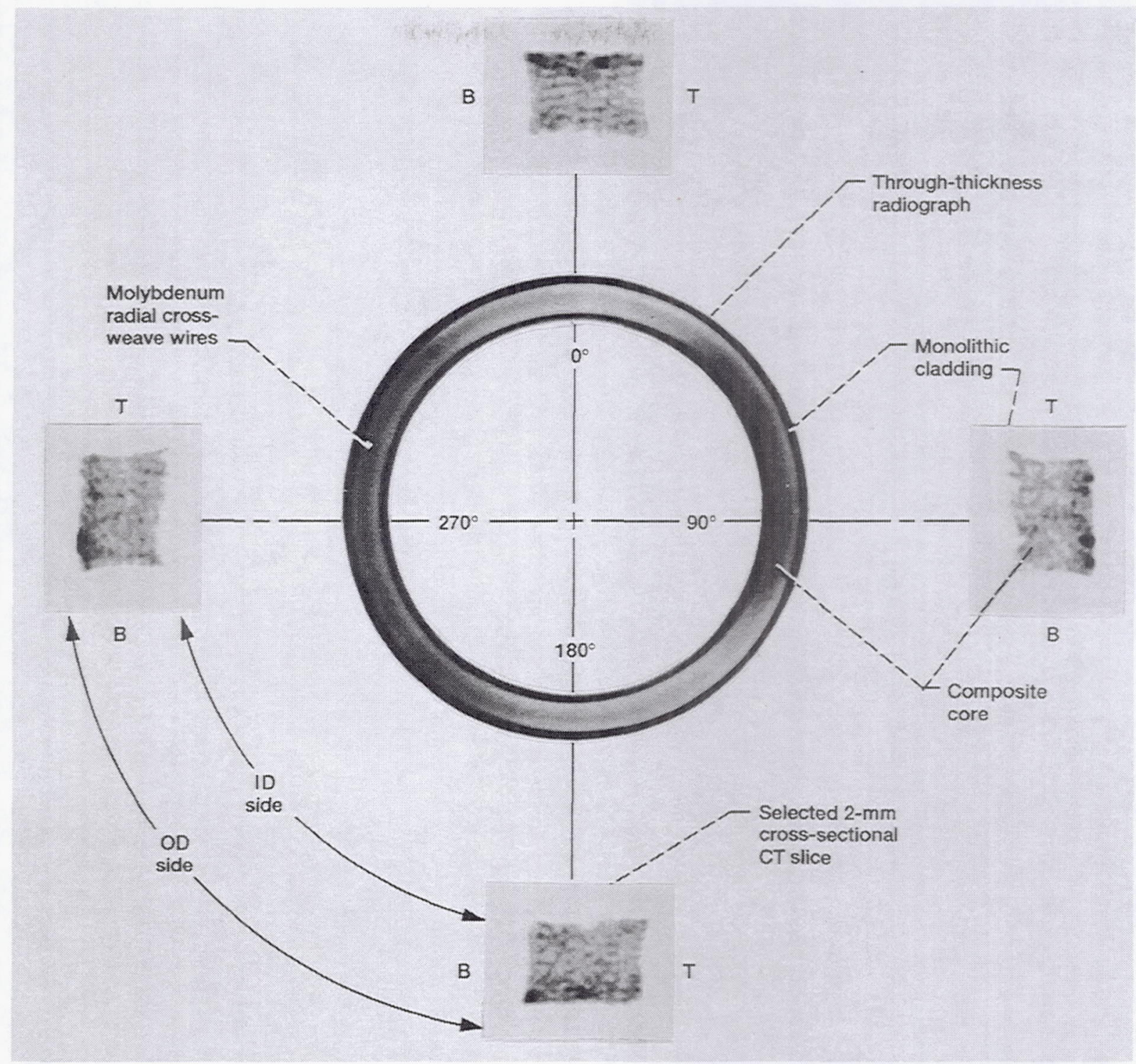

FIGURE 14.-RADIOGRAPHY AND X-RAY COMPUTED TOMOGRAPHY OF RING R3. (ANNULUS DIMENSIONS: OD, 171 MM; ID, 133 MM; THICKNESS, 24 MM. ANNULUS MATERIALS, SCS-6/TI-15V-3CR-3AL-3SN. T IS TOP SIDE; B IS BOTTOM SIDE.) LIGHTER REGIONS INDICATE HIGHER DENSITY IN TOMOGRAPHY (DARKER IN RADIOGRAPHY).

and under different loading conditions, have been detected by $\mathrm{XCT}$ and incorporated in life prediction models (Gravet and Delaneuville, 1993; Halford, 1993; Chamis, 1993; and Holland and Zaretsky, 1993). Consequently, design and test engineers can concurrently decide whether to continue testing defective components or section them for detailed evaluation in order to further identify sources of manufacturing problems. NDE coupled with destructive verifications will certainly help accelerate the improvement of composite components.

$\mathrm{XCT}$ information helps manufacturers avoid machining through fibers, as in the case of the protruding cusp in all rings. The manufacturer now uses XCT images to guide machining of components to final dimensions.

Three-dimensional XCT density information of composite components can guide geometric modeling of composite constituents, composite stiffness modeling, and damage evolution modeling. Engineering tomography, which incorporates XCT density information in finite element modeling, should help in predicting life and serviceability of composite components. 


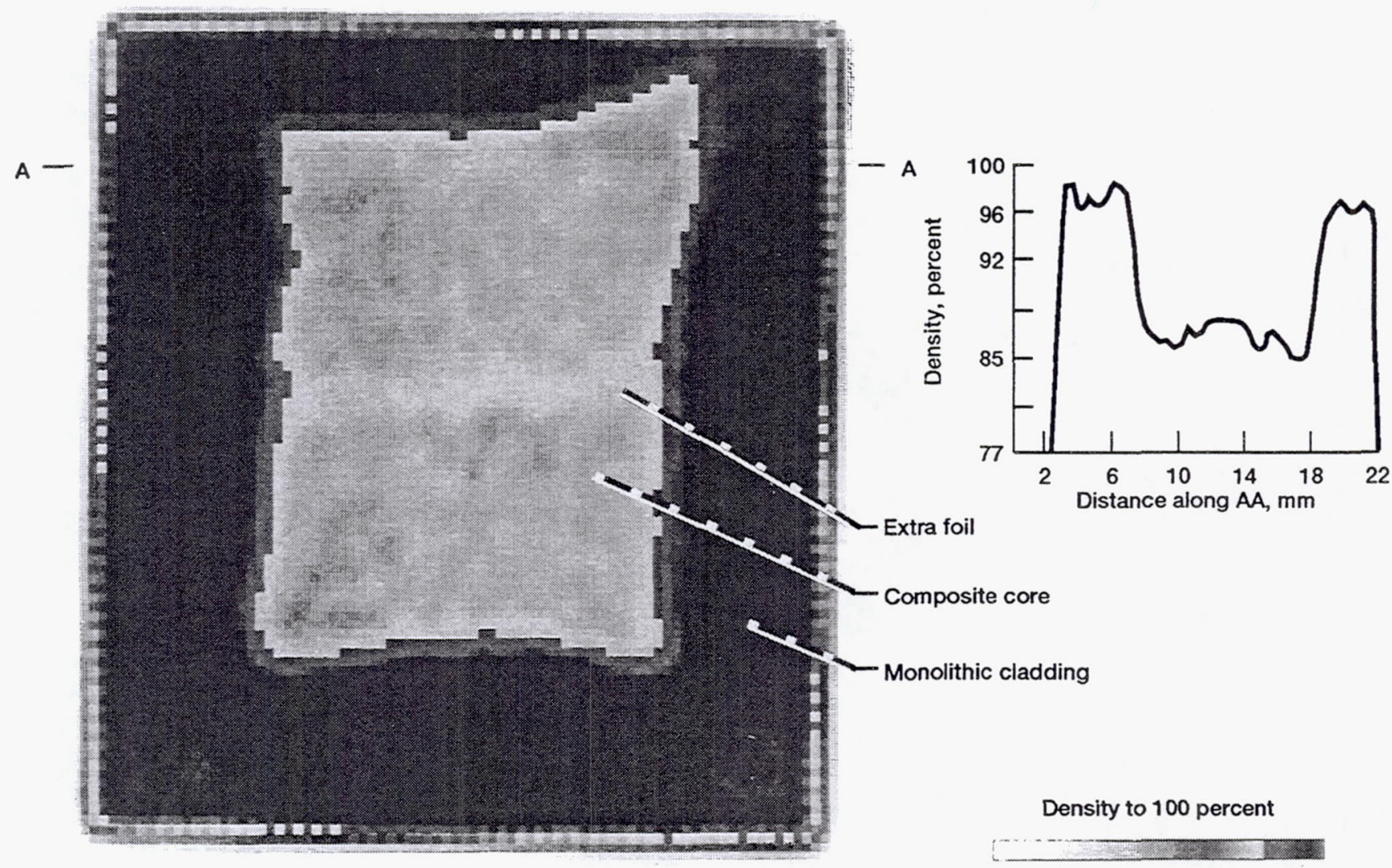

FIGURE 15. SELECTED XCT CROSS-SECTION FROM RING R1 SHOWING DENSITY VARIATIONS.

Predicting the life of components cannot be based only on coupon test results because the mechanical behavior of components is affected by different fabrication processes that are unique to specific component fabrications. Additionally, such issues as the nature of the loading, the mean residual stresses, the multiaxial state of stress, and the size effects are componentdependent distinctive characteristics (Halford, 1993). Thus, XCT in specific, and often NDE modalities in general, help reduce engineering approximation approaches, improve statistical inter- pretation (imaging modalities are the source of a very large data base) of life and deterministic life prediction analyses, and ameliorate and accelerate damage tolerance assessment.

Results from coupon testing and evaluation, coupled with materials characterization of related subscale components, can immensely improve component structural modeling and life prediction. This modeling and prediction would be otherwise nonattainable, because of the enormous cost attached to modeling based on direct testing of subscale components. 


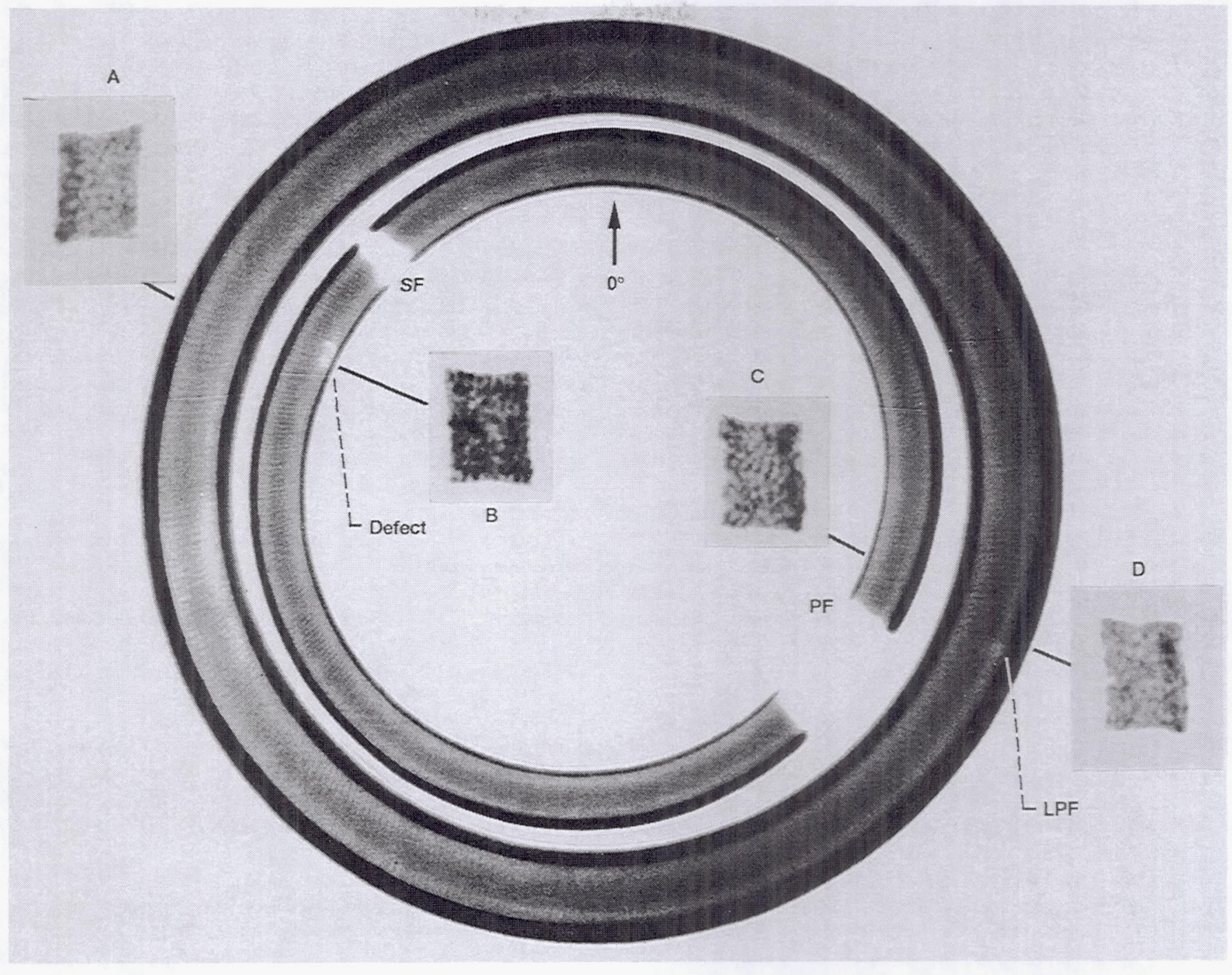

FIGURE 16.-RADIOGRAPHY AND SELECTED X-RAY TOMOGRAPHIC SLICES OF RING R2 BEFORE (OUTER RING) AND AFTER (INNER RING) BURST TEST. SLICES A AND D WERE TAKEN BEFORE BURST TESTING; SLICES B AND C, AFTERWARD. (PF = PRIMARY FRACTURE; SF = SECONDARY FRACTURE; LPF = LOCATION OF PRIMARY FRACTURE.) LIGHTER REGIONS INDICATE HIGHER DENSITY IN TOMOGRAPHY (DARKER IN RADIOGRAPHY).

\section{CONCLUSION}

The capabilities of $\mathrm{x}$-ray computed tomography and ultrasonics in characterizing metal matrix composite subscale engine rings were investigated and found viable. Spatial density information, which can be incorporated in finite element modeling of composite spatial stiffness and in geometric modeling of composite constituents, was provided and utilized in life prediction of $\mathrm{MMC}$ rings. It can be inferred that $\mathrm{x}$-ray computed tomography is a viable technique for accelerating the development of composite components. X-ray computed tomographic imaging can identify problems with manufacturing processes, guide machining of components to final dimensions, and lead structural and design engineers to realistic componentlife-prediction models.

Pulse-echo ultrasonics can detect damaged fibers and fibermatrix interface anomalies. However, more innovative techniques such as signal processing are needed to unambiguously decouple combined damage conditions.

Acousto-ultrasonics can assess the cladding-composite interface discontinuities or degradations and, with shear waves propagating perpendicular to fiber directions, can evaluate localized damage states. 


\section{ACKNOWLEDGMENTS}

The authors thank Howard B. Jones and Richard D. Chenail from the Materials Analysis Group at Pratt \& Whitney, West Palm Beach, FL, for the metallography support. We are greatful to Mr. James Bodis and Richard Rauser from Sverdrup Technology, Inc., Lewis Research Center Group, who provided helpful assistance in ultrasonics and radiography. Thanks are also extended to Mr. Michael E. Hughes from Advanced Research and Applications Corporation (at Wright-Patterson Air Force Base under contract F33615-88-C-2823) for the CT evaluation support.

\section{REFERENCES}

Baaklini, G.Y., 1992, "X-ray Attenuation Measurements for High Temperature Materials Characterization and In-Situ Monitoring of Damage Accumulation," NASA TM-105577.

Chamis, C.C., Murthy, P.L.N., and Singhal, S.N., 1993, "Computational Simulation of Hot Composite Structures," To be presented at the 10th Biennial Conference on Reliability, Stress Analysis and Failure Prevention, Albuquerque, NM, Sept. 19-22.

Dos Reis, H.L.M., 1991, "Acousto-Ultrasonic Evaluation of Ceramic Matrix Composite Materials," NASA CR-187073.

Gravett, P.W., and Delaneuville, R.E., 1993, "A Life Prediction Method for Matrix Dominated Fatigue Failure of SCS-6/Ti15-3 MMC," To be presented at the 10th Biennial Conference on Reliability, Stress Analysis and Failure Prevention, Albuquerque, NM, Sept. 19-22.

Halford, G.R., 1993, "MMC Ring Fatigue and Fracture Life Prediction-An Engineering Model," To be presented at the 10th Biennial Conference on Reliability, Stress Analysis and Failure Prevention, Albuquerque, NM, Sept. 19-22.

Halmshaw, R., 1987, "Non-Destructive Testing: Metallurgical and Materials Science Series," Edward Amold, Baltimore, p. 130 .

Holland, F.A., Zaretsky, C.V., and Mellis, M.E., 1993, "Probabilistic Failure Prediction of an SCS-6/Ti-15-3 MMC Ring," To be presented at the 10th Biennial Conference on Reliability, Stress Analysis and Failure Prevention, Albuquerque, NM, Sept. 19-22.
Kautz, H.E., and Lerch, B.A., 1991, "Preliminary Investigation of Acousto-Ultrasonic Evaluation of Metal-Matrix Composite Specimens," Materials Evaluation, 49, pp. 607-612. (Also NASA TM-104339.)

Kautz, H.E., and Bhatt, R.T., 1991, "Ultrasonic Velocity Technique for Monitoring Property Changes in FiberReinforced Ceramic Matrix Composites," Proceedings of the 15th Annual Conference on Composites and Advanced Ceramic Materials, Pt. 1, Ceramic Engineering and Science Proceedings, Vol. 12, pp. 1139-1151. (Also NASA TM-103806).

Kautz, H.E., 1992, "Detecting Lamb Waves with Broadband Acousto-Ultrasonic Signals in Composite Structures," $\underline{\mathrm{Re}-}$ search in Nondestructive Evaluation, Vol. 4, No. 3, pp. 151-164. (Also NASA TM-105557).

Lott, L.A., and Kunerth, D.C., 1990, "NDE of Fiber-Matrix Bonds and Material Damage in Ceramic/Ceramic Composites," ASNT, Conference on Nondestructive Evaluation of Modern Ceramics, Columbus OH, July 9-12, 1990, pp. 135-139.

Nondestructive Testing Methods Specification, Spec. No. SIM-1, Change K, pp. 1-25, Pratt \& Whitney.

Petrasek, D.W., 1988, "High Temperature Engine Materials Intermetallic Matrix Composites," HITEMP Review 1988 , NASA CP-10025, pp. 67-81.

Petrasek, D.W., 1989, "Intermetallic Matrix Composites," HITEMP Review 1989, NASA CP-10039, pp. 8-1-8-13.

Stephens, J.R., 1990, "Hitemp Program Overview," HITEMP Review 1990, NASA CP-10051, pp. 1-1-1-23.

Tewari, A.T., and Henneke II, E.G., "Real Time AcoustoUltrasonic NDE Technique to Monitor Damage in SiC/CAS Ceramic Composites Subjected to Dynamic Loads," Proceedings of the ASTM Second Symposium on Cyclic Deformation, Fracture, and NDE of Advanced Materials, Miami, FL, November 16-17, 1992 (In press).

Yancey, R.N., and Baaklini, G.Y., 1993, "Computed Tomography Evaluation of Metal-Matrix Composites for Aeropropulsion Engine Applications," 93-GT-4, ASME Turbo Expo, Cincinnati, OH, May 24-27. Also accepted for publication in the transactions of the ASME. 


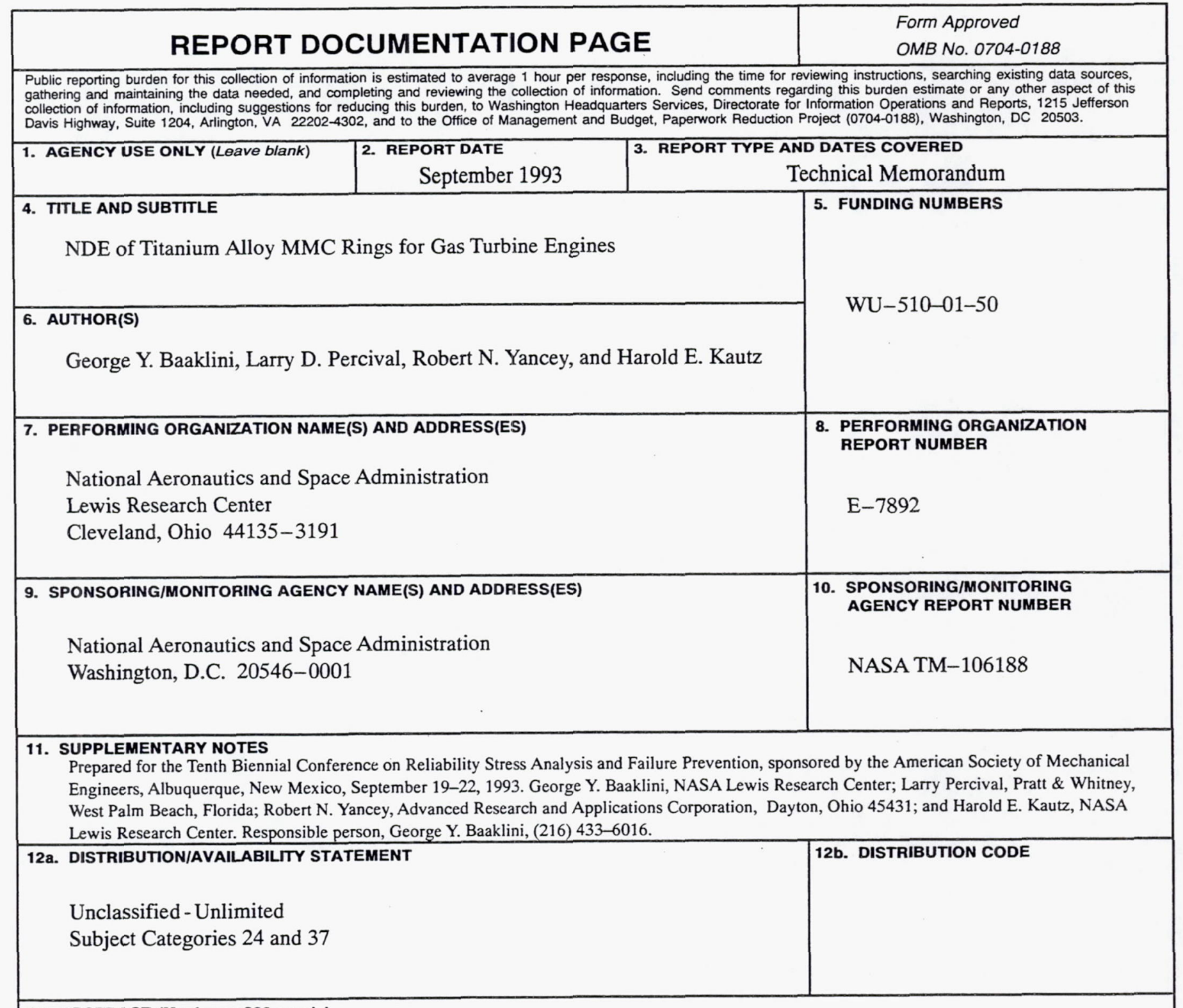

13. ABSTRACT (Maximum 200 words)

Progress in the processing and fabrication of metal matrix composites (MMC's) requires appropriate mechanical and nondestructive testing methods. These methods are needed to characterize properties, assess integrity, and predict the life of engine components such as compressor rotors, blades, and vanes. In this paper capabilities and limitations of several state-of-the-art nondestructive evaluation technologies are investigated for characterizing titanium MMC rings for gas turbine engines. We examined the use of NDE technologies such as x-ray computed tomography, radiography and ultrasonics in identifying fabrication-related problems that caused defects in components. Acoustoultrasonics was explored to assess degradation of material mechanical properties by using stress wave factor and ultrasonic velocity measurements before and after the burst testing of the rings.

\section{SUBJECT TERMS}

MMC; Alloy C; Ti-15-3; NDE; AU; Ultrasonics; Tomography; CT; Acoustoultrasonics; Nondestructive evaluation; NDT; NDI; Turbine engines

\begin{tabular}{|c|c|}
\hline $\begin{array}{c}\text { 17. SECURITY CLASSIFICATION } \\
\text { OF REPORT } \\
\text { Unclassified }\end{array}$ & $\begin{array}{c}\text { 18. SECURITY CLASSIFICATION } \\
\text { OF THIS PAGE } \\
\text { Unclassified }\end{array}$ \\
\hline
\end{tabular}

19. SECURTYY CLASSIFICATION OF ABSTRACT Unclassified 